Kong. Res. J. 2(2) : 135-138, 2015

ISSN 2349-2694

Kongunadu Arts and Science College, Coimbatore.

\title{
HISTOPATHOLOGICAL ALTERNATIONS INDUCED BY THE ACTION OF LAMBDA-CYHALOTHRIN IN ETROPLUS SURATENSIS (BLOCH)
}

\author{
Vidhya, $\mathbf{V}^{1}$. and C. Radhakrishnan Nair ${ }^{2}$ \\ ${ }^{1}$ Department of Zoology, Sree Ayyappa College for Women, Chunkankadai, Kanyakumari District. \\ 2PG and Research Centre, Department of Zoology, S.T. Hindu College, Nagercoil, Kanyakumari District. \\ E.mail: vidhyavkrishna@yahoo.com; rknairsthc@gmail.com
}

\begin{abstract}
The study of structural damage of organs or tissues is an integral part of pollution toxicology. The present work was conducted to study the effect of the pyrethroid insecticide, lambda-cyhalothrin on the kidney of the pearlspot "Etroplus suratensis". The dilation of the kidney tubules, degeneration in kidney tissue, rupture in the collecting tubules and necrosis were observed in the present investigation after lambdacyhalothrin treatment.
\end{abstract}

Keywords: E. suratensis, Kidney, Lambda-cyhalothrin.

\section{INTRODUCTION}

Histopathology is an effective tool to visualize the stress-induced structural changes in cells and tissues. Organisms have tremendous capacity to overcome the environmental stress conditions and thus to maintain the homeostasis. Various chemicals with their varied mode of action in different tissues bring about certain architectural changes ultimately culminating in either death of the organism or making the organism less viable for survival. Kidney plays a vital role in the maintenance of an organism's internal environment, being the key to the regulation of extracellular fluid volume and composition as well as acid-base balance. It is also a target of toxic chemicals, which can disrupt its functions, and cause temporary or permanent derangement of homeostasis. Several authors recorded histopathological changes in the kidney of freshwater fish, Puntius conchonius and Channa punctatus exposed to organophosphate insecticides diazinon, monocrotophos, dimethoate and elsan respectively (Banerjee and Bhattacharya, 1994; Miller, 2002). The toxicity of such pollutants is assessed by the extent of histopathological damages induced in the test organism and the degree of cell damage is evident in relation to the concentration of pollutants employed. Mortality of fishes occurs due to the pathological lesions caused by pollutants (Iyappan et al., 1998; Tilak et al., 2005).

The present work was conducted to study the effect of the pyrethroid insecticide, lambdacyhalothrin on the kidney of the pearlspot "Etroplus suratensis".

\section{MATERIALS AND METHODS}

Fishes were randomly selected from control and treated groups for histopathological observations by sampling after 60 days of pesticide exposure. The kidney of control and pesticide treated E. suratensis fishes were taken out and a histological study was carried out by employing Culling (1974) method.

\section{RESULTS}

The teleost kidney consists of head and body kidneys. Head kidney is the anterior portion of the kidney and consists of lymphoid tissue. Body kidney is composed of many nephrons and intestitial lymphoid tissue. The interstitial tissue is the major hematopoietic tissue in the body. Each nephron consists of two parts, the glomerulus and the urinary tubule. The bowman's capsule consists of an inner and outer layer of single flattened epithelia. Renal tubules consist of single layer of epithelial cells. Mesangium fills the spaces between the loops of glomerular capillaries (Fig. 1). In lower concentration (0.005 ppm), kidney of E. suratensis exposed to lambda-cyhalothrin histological alternations included degeneration and atrophy of renal tubules and vacuolization were observed (Fig. 2). In E. suratensis exposed to $0.006 \mathrm{ppm}$ of lambdacyhalothrin for 60 days, showed the cells of the kidney are destroyed, vacuolization, collapsing glomeruli, congestion of cells and necrosis were noticed (Fig. 3). 
Fig. 1: Section showing the kidney of control E.suratensis (400X)

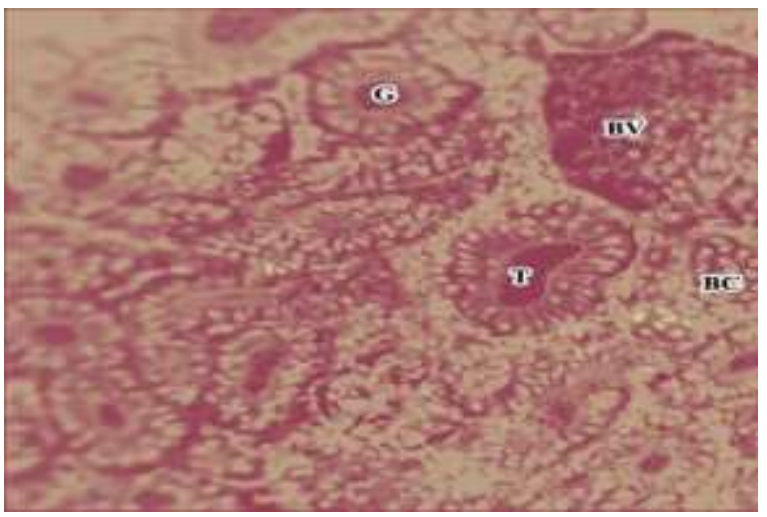

G-Glomerulus BV-Blood vessel T- Tubule BC-Bowman's capsule

Fig. 2: Section showing the kidney of E.suratensis exposed to $0.005 \mathrm{ppm}$ concentration of lambdacyhalothrin (400X)

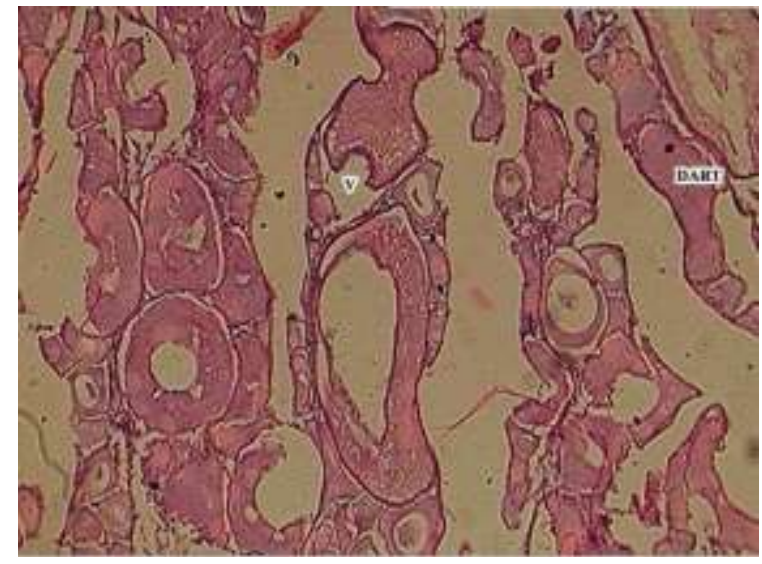

DART - Degeneration and atrophy of renal tubules V-Vacuolized

Fig. 3: Section showing the kidney of E.suratensis exposed to $0.006 \mathrm{ppm}$ concentration of lambdacyhalothrin (400X)

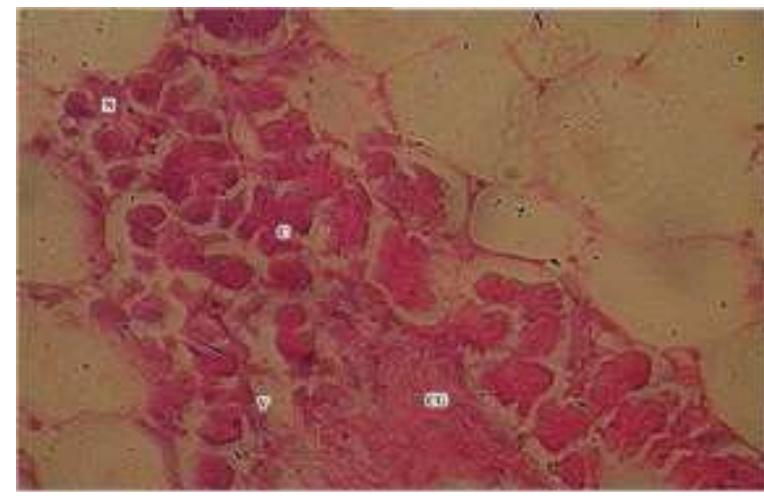

CG-Collapsing glomeruli V-Vacuole N-Necrosis C-Congession of cells
Fig. 4: Section showing the kidney of E.suratensis exposed to $0.008 \mathrm{ppm}$ concentration of lambdacyhalothrin $(400 \mathrm{X})$

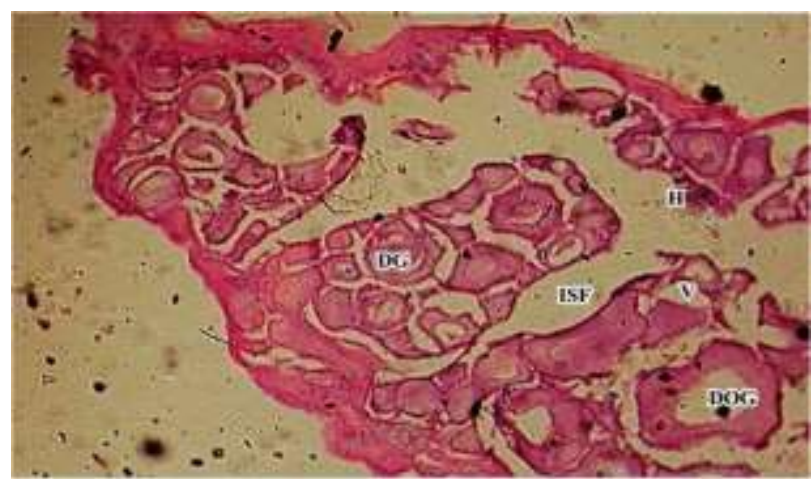

DG - Degeneration in glomerulus DOG-Disorganization of glomerulus V-Vacuolization H-Haemorrhage ISF-Intercellular spaces formation

Fig. 5: Section showing the kidney of E.suratensis exposed to $0.013 \mathrm{ppm}$ concentration of lambdacyhalothrin (400X)

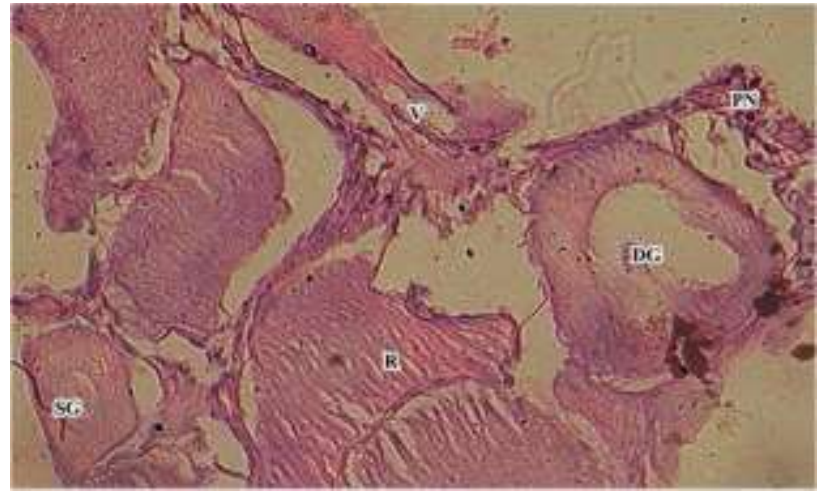

SG-Swelling of glomerular cells R-Ruptered cells DG-Damaged glomerulus PN - Pycnotic nuclei, V-Vacuolization

Fig. 6: Section showing the kidney of E.suratensis exposed to $0.026 \mathrm{ppm}$ concentration of lambdacyhalothrin $(400 \mathrm{X})$

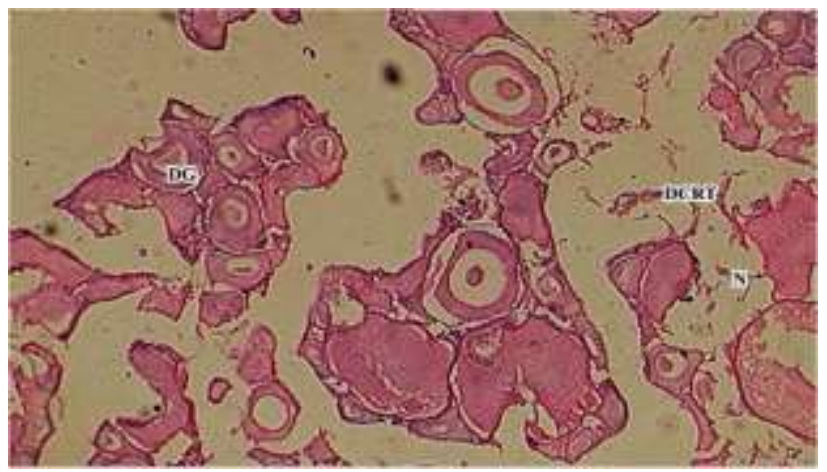

DG - Degeneration in glomerulus N-Necrosis DCRT-Dilation in the capillary tubes of renal tubules. 
At middle concentration of lambdacyhalothrin $(0.008 \mathrm{ppm}), \quad$ vacuolization, haemorrhage, intercellular spaces formation, disorganization and degeneration of glomerulus were identified (Fig. 4). The kidney of E.suratensis exposed to sub-lethal concentrations of lambdacyhalothrin $(0.013 \mathrm{ppm}$ and $0.026 \mathrm{ppm})$ histological alternations like swelling of glomerular cells, ruptered of kidney cells, damaged glomerulus, vacuolization, pycnotic nuclei, degeneration of glomerulus, dilation in the capillary tubes of renal tubules and necrosis leading to the complete necrosis were noticed (Figs. 5 and 6).

\section{DISCUSSION}

Kidney is an important organ of excretion and osmoregulation and is highly susceptible to toxic substance because of its high blood supply. In fish, as in higher vertebrates, the kidney performs an important function to maintain the homeostasis. The kidney is one of the first organs to be effected by contaminants in water (Thophon et al., 2003). The major alternations found in the kidney of $E$. suratensis exposed to lambda-cyhalothrin are degeneration and atrophy of renal tubules, vacuolization, collapsing glomeruli, congestion of cells, necrosis, haemorrhage, intercellular spaces formation, disorganization and degeneration of glomerulus, swelling of glomerular cells, damaged glomerulus, pycnotic nuclei and dilation in the capillary tubes of renal tubules. All these changes were brought about by pesticide intoxication because kidney is an important organ for the filtration of blood (Radhakrishnan Nair, 2002). Similar results were reported in the severe necrosis, vacuoles around renal tubule and haemorrhage in histological section of the kidney of $C$. mrigala were observed when it exposed to fenvalerate (Anitha Susan and Tilak, 2003).

Pathological changes have earlier been reported in the kidney of fishes exposed to various pollutants (Banerjee and Bhatacharya, 1994). According to Mohamed (2009) the exposure of fish to pollutants, that is agricultural and industrial chemicals, resulted in several pathological changes in different tissues of fish. Cengiz (2006) observed degeneration in the renal tubule, pycnotic nuclei in the hematopoietic tissue and degeneration of glomerulus. Similar alterations in the kidney have also been reported in Nile Tilapia exposed to ammonia (Benli et al., 2008).

The dilation of the kidney tubules, degeneration in kidney tissue, rupture in the collecting tubules and necrosis as observed in the present investigation after lambda-cyhalothrin treatment have also been reported in various fish exposed to various pollutants (Sukumar and Karpagaganapathy, 1986; Gill et al., 1988; Vardhani and Gowri, 2002). According to Dubale and Shah (1981) the process of destruction is a function of dosage and period of exposure and they opined that the renal tubules of kidney are the first to be affected by pesticide stress. Rashatwar and Ilyas (1984) reported the histolopathological changes in kidney to lead to cloudy swelling of renal tubules in Nemachellus denisoni acutely exposed to phosphamidon.

In the present study, kidney of the fish often showed vacuolar degeneration (cloudy swelling) in tubules cells, characterized by the hypertrophy of the cells. In more severe cases, the degenerative process leads to tissue necrosis. The necrosis of the renal tubules affects the metabolic activities and promotes metabolic abnormalities in fish (Yokote, 1982). All these changes were brought about by pesticide intoxication because kidney is an important target organ for the filtration of blood. The present study was supported by various authors like King (1962) and Singh and Sahai (1986). Heptachlor also produced abnormality in the kidney tubules in L. rohita (Konar, 1970). Nephrotoxic lesion including degenerative changes in tubular epithelium, dilation of tubular lumina proteinaceous or cellular cast within tubular lumina, tubular necrosis, shrinkage of glomeruli, microvacuolar and degeneration was reported by Nestel and Budd (1975).

\section{REFERENCES}

Anitha Susan, T. and K.S. Tilak, (2003). Histopathological changes in the vital tissues of the fish Cirrhinus mrigala exposed to fenvalerate technical grade. Poll. Res., 22(2): 179-184.

Banerjee, S. ansd S. Bhattacharya, (1994). Histopathology of kidney of Channa punctatus exposed to chronic nonlethal level of elsan, mercury and ammonia. Ecotoxicology and Environ. Saf. 29(3): 265-275.

Benli, A.C.K., G. Koksal and A. Ozkul, (2008). Sublethal ammonia exposure of Nile Tilapia (Oreochromis niloticus L.): Effects on gill, liver and kidney histology, Chemosphere, 72: 13551358.

Cengiz, E.I., (2006). Gill and kidney histopathology in the freshwater fish Cyprinus carpio after acute 
exposure to deltamethrin. Environmental Toxicology and Pharmacology. s: 200-204.

Culling, C.F.A., (1974). Handbook of histopathological and histochemical techniques, $3^{\text {rd }}$ edition.

Dubale, M.S. and P. Shah, (1981). Histopathology of the kidney of the fish, Channa punctatus exposed to cadium. J. Anim. Morphol. Phyxiol., 28(1-2): 166-171.

Gill, T.S., C.P. Jagdish and P. Jaishree, (1988). Gill, liver and kidney lesions associated with experimental exposure to carbaryl and dimethoate in fish, Puntius conchonius (HAM.). Bull. Environ. Contam. Toxicol., 41: 71-78.

Iyappan K., A.M. Rao, V. Mathivanan and P.R. Karpagaganapathy, (1998). Fish kills in the Uppanar estuary-An indication of abnormal aquatic pollution. Proc. Sem. Expos. Environ. Stat. Tamilnadu 'Flora'. Erode, India.

King, F., (1962). Some effects of DDT on guppy and brown trout. Trans. Amer. Fish Soc., 92: 372.

Konar, S.K., (1970). Some effects of sublethal levels of heptahlor on Labeo rohita. J. Inland Fish. Soc., India, 2: 51-54.

Miller, D.S., (2002). Xenobiotic export pumps, endothelin signalling, and tubular nephrotoxicantsa case of molecular hijacking. J. Biochem. Mol. Toxicol., 16: 121-127.

Mohamed, F.A.S., (2009). Histopathological studies on Tilapia zillii and Solea vulgaris from Lake Qarun, Egypt. World J. Fish. Mar. Sci., 1:29-39.

Nestel, H. and J. Budd, (1975). Chronic exposure of rainbow trout (Salmo gairdneri) to a polychlorinated biphenyl (Aroclor 1254):
Pathological effects. Can. J. Comp. Med., 39: 208225.

Radhakrishnan Nair, C., (2002). Studies on pesticideinduced changes in chosen fishes. Ph.D. Thesis, Manonmaniam Sundaranar University, Tirunelveli, India.

Rashatwar, S.S. and R. Ilyas, (1984). Effect phosphamidon in freshwater teleost fish Nemacheilus denisoni (Day). Histopathological and biochemical studies. J. Environ. Biol., 5(1): 1-18.

Singh, S. and S. Sahai, (1986). Accumulation of malathion in the gills, liver and kidney of Puntias ticto as assessed by TLC. J. Environ. Biol., 7: 107-112.

Sukumar, A. and P.R. Karpagaganapathy, (1986). Renal dysfunction in a freshwater fish, Colisa lalia after carbofuran intoxication. In. Environmental and Ecotoxicology. (Eds. Dalela Rc. Shashi Y.N. and Gupta). Acad. Environ. Biol. India., 243-247.

Tilak, K.S., D. Koteswara Rao. and K. Veeraiah, (2005). Effects of chlorpyrifos on histopathology of fish Catla catla. J. Ecotoxicol. Environ. Monitor., 15(2): 127-140.

Vardhani, V.V. and Gowri, (2002). Antigen induced histopathological changes in liver and kidney of Labeo rohita. J. Ecotoxicol. Environ. Moint., 12(1): 209-213.

Yokote, M., (1982). Digestive system. In: An atlas of fish histology-normal and pathological features (T. Hibiya, Ed.). Kodansha Ltd., Tokyo, p. 74-93. 